\title{
AMERICAN MUSEUMS IN THE 21ST CENTURY
}

\author{
W. RICHARD WEST \\ A public lecture at the National Museum of Australia, Canberra \\ 26 February 2002*
}

$\mathrm{T}$ he title of my presentation is my effort to construct an analytic umbrella large enough to encompass several interrelated aspects of the term 'authority' that hazve piqued my interest in my capacities as Director of the Smithsonian Institution's National Museum of the American Indian and former Chair of the American Association of Museums. Indeed, in both of these capacities and over the past several years, I can think of no other word in the English language that has come up with more frequency in American museums than the term 'authority'.

I want to discuss today the issue of authority as it relates to the interpretation and representation of the objects, ideas, and peoples that are encompassed by the work of a museum. I would like to do so, initially, by tracing, ever so briefly, the history of museum representation and interpretation, following it through its evolution to its rather changed present state in America. I then will turn, by way of practical example, to the work of the National Museum of the American Indian regarding matters of representation and interpretation, not because I consider it the definitive illustration, but only because it is the institutional setting for this issue that I obviously know best, and where, I might add, these questions take on the reality of virtual inevitability.

Historically, most of us who have been involved with museums for any length of time would agree, I believe, that museums have been rather precious places - indeed, temples where representational or inter pretive truth has been the sanctuary of a narrowly defined and largely self-appointed museological priesthood. To this point, in an article entitled, "The Museum: A Temple or the Forum", Duncan Cameron has described this past in the following way:

... [T]hose segments of society with the power to do so ... created museums which were the temples within which they enshrined those things which they held to be significant, important and of value. The public generally accepted the idea that if it was in the museum, it was not only real, but represented a standard of excellence. If the museum said that this and that was so, then that was a statement of truth. [Emphasis added.]

Even though this cultural preserve known as the museum was monopolised from the inside of museums for the better part of a century, over time, due to this very aura of cultural and artistic authority that was ascribed to museums, they ultimately and almost inevitably became contested ground. As Carol Duncan has observed and predicted in her essay entitled "Museums and Citizenship":

Museums and museum practices can become objects of fierce struggle and impassioned debate. What we see and do not see in our most prestigious ... museums - and on what terms and whose authority we do or don't see it - 
involves the much larger questions of who constitutes the community and who shall exercise the power to define its identity.

These tensions derive, as Duncan points out, from the belief on the part of those outside of museums that authority with respect to the representation and interpretation of objects, ideas, and peoples should not be imposed exclusively from within. In a thoughtful essay entitled "Exhibition in Japanese Culture", Masao Yamaguchi explains how the very presentation of Japanese objects in an art museum can represent, in effect, the elevation of an art curator's authority over the authority of those who created the objects in the first instance:

Commodities in their original context were not meant to be of artistic value. They turn into a kind of simulacrum of life once they are taken out of the flow of life, and acquire a kind of autonomy at the cost of their position in relation to everyday life.

In a recent article that appeared in the Bulletin of the Smithsonian's Center for Museum Studies, Jonathan Yorba, a faculty member in a department of museum studies, offers a second and almost identical example from the viewpoint of Latinos and the Latino community:

Objects entrusted to museum collections did not appear magically; they were/are shaped by human hands - by people who were/are part of a community. Therefore, at the fore of any museum's mission statement should be a sincere commit-ment to community, in all its multifarious meanings. Community members bring a fresh perspective - a lived experience from within the community.

We need to move so-called mainstream museums beyond their ... often one-dimensional representations of Latinos/as by bringing together diverse represent-atives from
Latino communities and museum professionals to discuss ways to more fully represent the material and visual culture of Latinos/as.

Duncan Cameron, whom I quoted earlier, has echoed these sentiments by arguing that, as an antidote, we need museums that honour a new and different model and that provide different conceptual space. Quoting again from his essay, "The Museum: A Temple or the Forum":

[Museums] ... must meet society's need for that unique institution which fulfills a timeless and universal function - the use of a structured sample of reality, not just as a reference but as an objective model against which to compare individual perceptions. At the same time, and with a sense of urgency, the forums must be created, unfettered by convention and established values. The objective here is neither to neutralize nor to contain that which questions the established order. It is to ensure that the new and challenging perceptions of reality, the new values and their expressions, can be seen and heard by all.

In the Introduction to the book they edited entitled Exhibiting Cultures, the Poetics and Politics of Museum Display, Steven Lavine and my former colleague at the Smithsonian, Ivan Karp, emphasise the importance of Cameron's point in somewhat different and more purely museological terms:

Museums attempting to act responsibly in complex, multicultural environments are bound to find themselves enmeshed in controversy. Only when as a society we have achieved sufficient opportunity for art and artifacts of "other" cultures to be seen can we expect this kind of controversy to become less heated....

In the meantime, the museum world needs movement in at least three arenas: 1 . the 
strengthening of institutions that give populations a chance to exert control over the way they are presented in museums; 2 . the expansion of the expertise of established museums in the presentation of nonWestern cultures and minority cultures in the United States; and 3. experiments with exhibition design that will allow museums to offer multiple perspectives or to reveal the tenden-tiousness of the approach taken.

So what do I infer from this theory and these examples about the present state of American museums and their possible future directions? With the essential qualifier that I am only one museum director among many whose views often are as diverse as our numbers, let me offer the following two observations and comments - with a dash of value judgment.

My first observation is that American museums are well on their way, and have been for the better part of the past decade, to a position of shared authority with respect to the representation and interpretation of cultures and the arts that is their raison d'etre. The components of this movement are twofold and are both external and internal to the museum community.

First, much of the motivation comes from within the museum community itself, as museological theory and associated best practices have altered, sometimes only incrementally but almost always ineluctably, through the past generation, moving from the temple of yore with its metaphorically locked doors and few windows to a place and space with many more doors and windows that connect to the outside - and that open more easily and frequently. Second, from an external standpoint, America's museums have had - and perhaps should have had little choice given the rapidly diversifying contemporary cultural makeup of the United States and an associated recognition that much of this diversity has existed within the United States for generations in any event. This awakening has caused the realisation, which continues to gain wider credence in the museum community, that perhaps all people with a legitimate claim to representational and interpretive authority may not view material culture and art in the same way.

My second observation is that this dynamic, the widening of the concept of authority within America's museums, is having a singularly transformative effect on these institutions - they are becoming by nature and in concept somewhat different places. Obviously, the voices visitors hear in museums, through scholarship, exhibitions, and public programs, under these circumstances, are more multiple and often more diverse in viewpoint. The transformation I refer to, however, goes beyond this kind of distinction about what visitors see and hear to the essential nature of the institution, and it is this: America's museums are becoming far more the forums of which Duncan Cameron spoke earlier and far less the unitary temples of the past.

Here I will add a value judgement, which I emphasise is only my own and which I appreciate is debated, sometimes vigorously, within the American museum community: I personally applaud this transformation of American museums and for several reasons. First, I believe, based upon my own experience at the National Museum of the American Indian, which I will describe in a moment, that an approach based upon shared authority can enhance dramatically the quality of the museum's work because it widens and deepens the scope of museum scholarship, exhibitions, and public programming - and thus redounds to the direct benefit of those millions of people who walk through these places every year.

Second, I also believe that the concept of a museum as a true forum, a gathering place where a multiplicity of diverse and authoritative viewpoints can coexist and even be debated, has a salutary impact on 
museums and the communities in which they sit. The museum as forum draws closer to the community of which it is a part, has a more multifaceted and integral set of connections to it, and, in relation to the community, becomes perceived by its members as a different kind of place - as a bona fide and essential civic place and space rather than only a cultural destination to be visited periodically if possible.

As an illustration of all of the above, I would like to turn now to the National Museum of the American Indian and, more specifically, to its experience in developing the inaugural permanent exhibition installations for its museum on the National Mall in Washington, D.C., which is currently under construction and scheduled to open in the fall of 2004. I wish to emphasise again, as I mentioned before, that I do not presume the status of sacrosanctity for anything we have done, but it is museum work that is relevant to what I have just discussed and with which I am intimately familiar.

As a starting point for what I am about to describe, I would like to offer the following comments by way of introduction and brief background. I begin by invoking the eloquence of my first boss at the Smithsonian Institution, Secretary Robert McCormick Adams, who oversaw the agreements and congressionallegislation that established the National Museum of the American Indian as a part of the Smithsonian Institution in 1989. Here is how he conceptualised the intellectual superstructure of the Museum at its inception:

...[W]e move decisively from the older image of the museum as a temple with its superior, self-governing priesthood to ... a forum ... committed not to the promulgation of received wisdom but to the encouragement of a multicultural dialogue.

This is a national museum ... [that] takes the permanence ... the authenticity ... the vitality and the selfdetermination of Native American voices ... as the funda-mental reality ... it must ... represent.

From this vision of the National Museum of the American Indian, with which I concurred explicitly and wholeheartedly and without which I would not have become a recovering lawyer, the staff and Board of Trustees of the Museum fashioned the following Mission Statement, which to this day remains the NMAI's controlling guidepost in all its work. The Statement reads as follows:

The National Museum of the American Indian shall recognize and affirm to Native communities and the non-Native public the historical and contemporary cultural achievements of the Native peoples of the Western Hemisphere by advancing, in consultation, collaboration, and cooperation with Native people, knowledge and understanding of Native cultures, including art, history, and language, and by recognizing the museum's special responsibility, through innovative public programming, research, and collections, to protect, support, and enhance the development, maintenance, and perpetuation of Native culture and community.

Based upon this Mission Statement, drafted by its staff and adopted by its Board of Trustees a decade ago, the Museum has been committed, explicitly and consistently, to a fully collaborative and mutually participatory relationship with Native communities throughout the Western Hemisphere regarding its representation and interpretation of Native peoples and cultures in its research and programming, including exhibitions. To this end, in the case of all exhibitions we have undertaken to date, including those planned for the opening on the National Mall in Washington, D.C. in 
2004, the Museum has involved those being represented directly in the development of exhibitions, including themes, ideas, and the selection and interpretation of objects. I cannot overemphasise the importance of this process element that is embedded in the Museum's Mission Statement - it is truly process so important that it rises to the level of substance or, to state the point slightly differently, it is process that is substance for the NMAI.

The process for creating the permanent installations for the NMAI's centerpiece facility on the National Mall in Washington, D.C. was no exception to this operational rubric. Through a series of consultations that took literally the better part of three years and involved some two-dozen meetings with Native peoples from throughout the Hemisphere, the overarching themes or concepts for the three inaugural exhibitions were developed. Described by functional titles, the three exhibitions are Our Universes, which addresses Native philosophy, worldview, and cosmology; Our Peoples, which focuses on Native histories told in the first person rather than the third person voice; and Our Lives, which traces the personal and community identities of contemporary Native peoples and communities.

In addition to these three themes and as adjunct to their implementation, the NMAI developed five guiding principles that were based directly upon its consultations with Native communities regarding exhibitions and were to inform their development. The five Exhibition Principles are the following: (1) community: our tribes are sovereign nations; (2) locality: this is Indian land; (3) vitality: we are here now; (4) viewpoint: we know the world differently; and (5) voice: these are our stories.

With these themes and Exhibition Principles in hand, the Museum then followed a very specific protocol for approaching Native communities to invite their voluntary participation in creating, developing, and finalising the three permanent inaugural exhibitions. The protocol, briefly summarised, consisted of the following specific steps: (1) my letter of invitation to the specific Native community explaining the Museum's intentions and inviting the community's participation; (2) if the invitation was accepted (and to date none has been declined), a visit by the NMAI's staff to the community to explain further the thematic superstructure of the exhibitions; (3) the community's visit to the NMAI's Cultural Resources Center near Washington, D.C., where the collections of the community were assembled; (4) the community delegation's selection of objects for the exhibition and, through additional consultations, what the community wished to say about the objects and related ideas; and (5) a second return visit by NMAI staff to the community for its advice and counsel regarding the final exhibition product, including both content and design. At the present time the National Museum of the American Indian is working in various stages of this protocol with some twentynine Native communities throughout the Western hemisphere, six of them from Latin America, two from Canada, and the balance from the United States.

The Museum's engagement with its constituent communities, however, does not end with the completion of the exhibitions that will be the core of its inaugural installations in its centerpiece building on the National Mall in Washington, DC. Over time the NMAI intends to rotate each of these twenty-nine components out of Washington, D.C., and in some form, to the communities who originated them. This approach, as a quite practical matter, allows the Museum both to freshen periodically its permanent exhibitions and to invite other Native communities into its galleries. In my mind, literally and metaphorically, it also completes the circle of sharing, fuses the connection, makes 
truly real the collaboration, between the National Museum of the American Indian and contemporary Native communities throughout the Americas.

To conclude this illustration, let me describe as succinctly as possible the linkages between it and the museological theory I discussed earlier in my presentation. First, the National Museum of the American Indian is seeking, consistently and methodically, to share its authority with those whose voices, views, and cultural expertise it feels are equally authentic and valid. Second, the NMAI does not pretend to be a temple where 'truth' carries an upper case ' $T$ ' and is singular. It respects the reality that views of objects, ideas, art, and history can be multiple and still be individually valid, worthy, and truthful, and it also affirms the proposition that Native peoples themselves should have a place at the table and a role in the conversation. Finally, it seeks to build, to maintain, to sustain through time the relevance of the Museum as a cultural and social place and space to the Native community of which it should be an integral and important part.

In closing, I hope that this presentation has provided for you some sense and understanding of what at least one American museum director and former chair of the American Association of Museums thinks is going on in American museums. You should also know that, for better or worse, you are more responsible than you might appreciate for what this American museum director thinks. When I was a newly recovering lawyer and a puppy museum director a decade ago, I surveyed the museum world as best I could at the outset and immediately headed for the southern hemisphere where, in Australia and New Zealand, I saw progressive efforts and developments occurring that were directly relevant and highly instructive regarding everything I have discussed here today. They informed my thinking both as the Chair of the American Association of Museums and as Director of the Smithsonian's National Museum of the American Indian. I thank you most sincerely for that intellectual and spiritual mentoring and guidance - as I also thank you now for your kind attention today.

* Note: this paper does not include references to sources cited as it is a transcript of a speech. 